\title{
Health Effects of Fructose and Fructose-Containing Caloric Sweeteners: Where Do We Stand 10 Years After the Initial Whistle Blowings?
}

\author{
Luc Tappy ${ }^{1} \cdot$ Kim-Anne Lế ${ }^{2}$ \\ Published online: 24 June 2015 \\ (C) The Author(s) 2015. This article is published with open access at Springerlink.com
}

\begin{abstract}
Suspicion that fructose-containing caloric sweeteners (FCCS) may play a causal role in the development of metabolic diseases has elicited intense basic and clinical research over the past 10 years. Prospective cohort studies converge to indicate that FCCS, and more specifically sugarsweetened beverages (SSBs), consumption is associated with weight gain over time. Intervention studies in which FCCS or SSB consumption is altered while food intake is otherwise left ad libitum indicate that increased FCCS generally increases total energy intake and body weight, while FCCS reduction decreases body weight gain. Clinical trials assessing the effects of SSB reduction as a sole intervention however fail to observe clinically significant weight loss. Many mechanistic studies indicate that excess FCCS can cause potential adverse metabolic effects. Whether this is associated with a long-term risk remains unknown. Scientific evidence that excess FCCS intake causes more deleterious effects to health than excess of other macronutrients is presently lacking. However, the large consumption of FCCS in the population makes it one out of several targets for the treatment and prevention of metabolic diseases.
\end{abstract}

This article is part of the Topical Collection on Pathogenesis of Type 2 Diabetes and Insulin Resistance

Luc Tappy

Luc.tappy@unil.ch

Kim-Anne Lê

Kim-Anne.Le@rdls.nestle.com

1 Department of Physiology, Faculty of Biology and Medicine, University of Lausanne, Rue du Bugnon 7, 1005 Lausanne, Switzerland

2 Department of Public Health Nutrition, Nestlé Research Center, Vers-chez-les-blanc, Route du Jorat 57, 1000 Lausanne 26 , Switzerland
Keywords Sugars $\cdot$ Fructose $\cdot$ Metabolic syndrome $\cdot$ Insulin resistance $\cdot$ Lipotoxicity $\cdot$ Cardiovascular diseases

\section{Introduction}

Free fructose and sucrose are naturally present in fruits, vegetables, and honey, and have most likely been part of the human diet since the beginning of mankind. The level of fructose consumption remained however very low until the nineteenth century, when sugar became widely available at a low cost due to colonial trade. Of interest, the consumption of sugar was tightly linked with that of sweetened beverages, initially tea, coffee, and chocolate in the nineteenth century and later sodas at the beginning of the twentieth century $[1,2]$.

The debate about the effects of sugar on health is far from recent. In 1912, the French physician Paul Carton proposed [3] that human diseases were mainly related to the consumption of three deadly nutrients: alcohol, meat, and industrial sugar. In the 1960s, Yudkin proposed that pure, white, and deadly sugar, more than saturated fat, was instrumental in causing cardiovascular diseases $[4,5]$. The adverse effects of sugars remained however controversial, and another French physician, Gerard Debry, concluded after an extensive review of the literature until 1995 that there was little evidence to support a harmful effect of sugars [6].

The debate about sugar was relaunched in 2004, when Bray, Niels, and Popkins suspected a causal relationship between the increased consumption of high-fructose corn syrup (HFCS) and the rise in the obesity prevalence in the USA [7]. They proposed that fructose was specifically responsible for adverse health effects due to its specific metabolism. The initial whistle blowing incriminating novel industrially produced sweeteners was, in part, linked with the incorrect assumption that HFCS contained more fructose than sucrose. The actual 
fructose content of HFCS is somewhere between 42 and $55 \%$ total sugars and therefore shows little difference with sucrose. Several clinical studies comparing the effects of HFCS and sucrose concluded that these two sweeteners have very similar effects [8-10]. Nonetheless, many strong position statements were published in the scientific literature and in the lay press stating that sugar, and more specifically its fructose component, is a toxic substance and a major determinant of noncommunicable diseases [11-14].

Since this initial renewed interest in fructose-containing caloric sweeteners (FCCS), many research studies have been performed and many articles have been published, but the controversy continues. Several health organizations however concluded that consumption of added sugar should be drastically reduced to less than $5 \%$ total energy (http://www.who. int/nutrition/sugars_public_consultation/en/, https://www. gov.uk/government/consultations/consultation-on-draft-sacncarbohydrates-and-health-report); these recommendations appear at odds with reports from European Food Safety Agency [15] and the Institute of Medicine [16] which both concluded that scientific evidence was lacking to set up an upper level for sugar consumption.

In this position paper, we attempt to define what we have learned during these past 10 years, which questions have been unequivocally answered, and which novel questions arose. In this process, we did not perform a critical, systematic review of the impressive literature on the topic but mainly focused on relevant meta-analyses and critical, systematic reviews published between 2007 and February 2015.

\section{Why Did We Initially Suspect That FCCS Are Deleterious to Metabolic Health?}

A role of FCCS in the pathogenesis of metabolic diseases was originally supported by

- Animal studies, mainly performed in rodents, but also in other animal species, including non-human primates, which indicate that adding fructose or sucrose to the diet can lead to the development of obesity, insulin resistance, type 2 diabetes, dyslipidemia, and occasionally high blood pressure $[17,18]$. In most of these studies, highsugar-fed animals are used as an experimental model of obesity or metabolic diseases, and the effects of a high FCCS intake are not directly compared to other obesogenic high-fat-based diets which produce similar long-term metabolic alterations [19, 20]. As such, they unequivocally demonstrate that sugar can induce overeating, obesity, and metabolic diseases in spontaneously feeding animals, but come short of demonstrating that this effect is exclusively related to FCCS.
- A small number of human studies showing that a highfructose diet was occasionally associated with the development of dyslipidemia [21].

- Epidemiological data showing associations between FCCS intake and body weight or prevalence/incidence of metabolic diseases [7, 22-27].

- Allegations that fructose may be obesogenic because of its propension to stimulate de novo lipogenesis [23-27] or may elicit inadequate suppression of food intake because it does not increase the secretion of insulin and gut satietogenic hormones [28, 29].

\section{What Has Been Learned Over the Past 10 Years?}

Far too many original articles and reviews were published in the scientific literature during this period to review each one in detail here. Evaluating the impact of this large amount of studies can however be facilitated by several recent metaanalyses and critical, systematic reviews that can be grossly classified into (a) epidemiological studies, (b) clinical intervention studies, and (c) controlled mechanistic studies. The major meta-analyses published between 2007 and February 2015 [30-38, 39•, 40-42, 43••, 44, 45, 46••, 47, 48••, 49••, 50-52] are listed in Table 1, together with the type of studies included in the meta-analysis, its major results, and their authors' main conclusions.

Epidemiological studies are based on analysis of prospective data available from large cohort of subjects with multiple dietary evaluations over time and several years of follow-up on body weight or incidence of metabolic diseases. Such studies allow identifying statistical associations between dietary intake at initial assessment or dietary changes observed between two dietary assessments and subsequent health status. As such, they are highly valuable to assess the plausibility that FCCS may be associated with metabolic diseases in real-life situations [53]. They however do not allow identifying causal relationship between FCCS and health due to the many possible confounders [54].

Epidemiological prospective studies show a strong association between FCCS intake and body weight gain [40, 55, $56 \bullet \bullet$. Most studies specifically addressed the effects of sugar-sweetened beverage (SSB) consumption, however, and the association between consumption of sugar in solid foods and obesity is relatively understudied. The results indicate that SSB consumption is strongly associated with higher total energy intakes [57], and that either SSB, total fructose, or total FCCS consumption is strongly associated with body weight gain over time. They however also indicate that other dietary food components, mainly fried potatoes, red meat, and processed meat, are also involved in body weight gain [56••]. Furthermore, FCCS consumption is also associated with the 


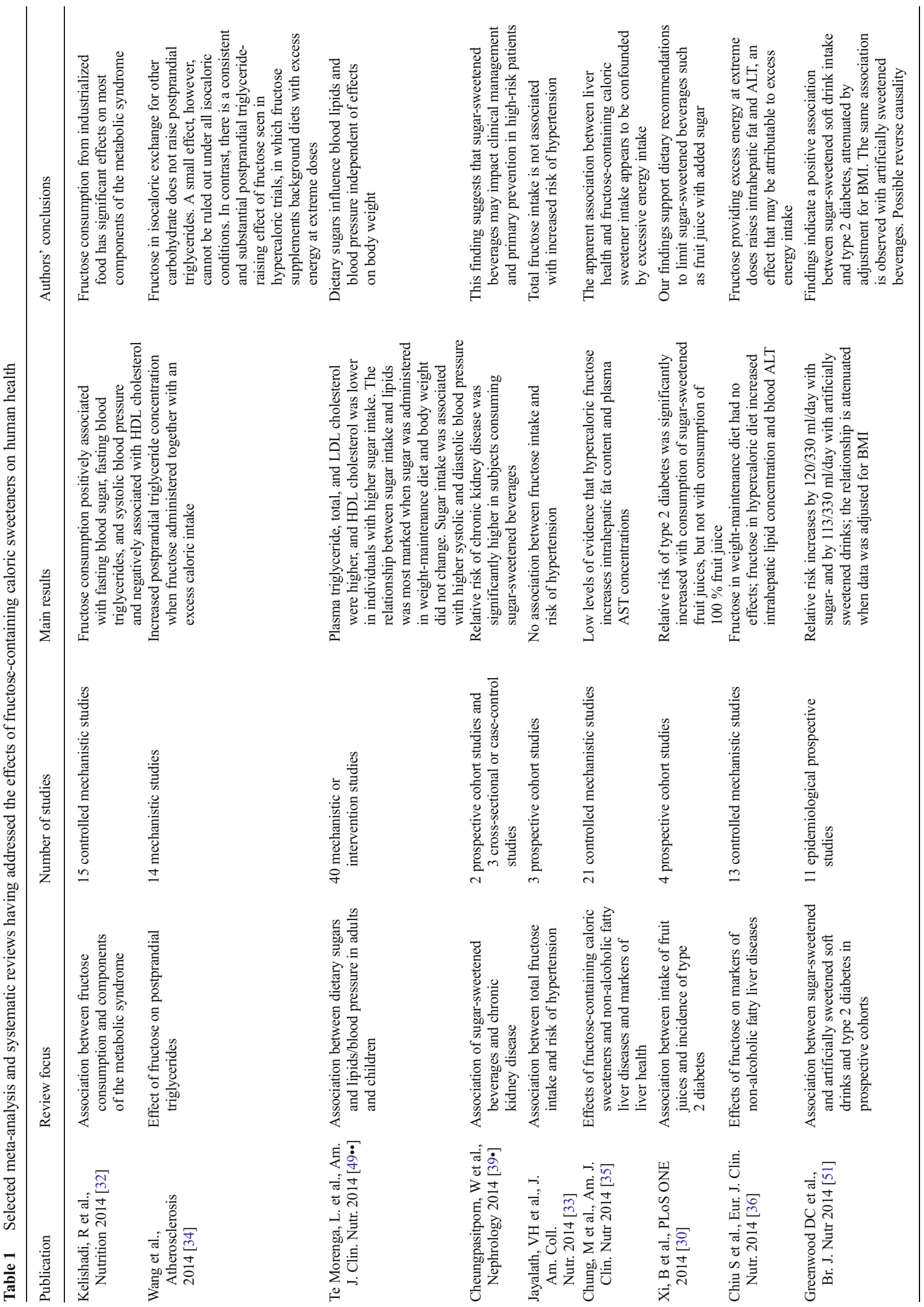




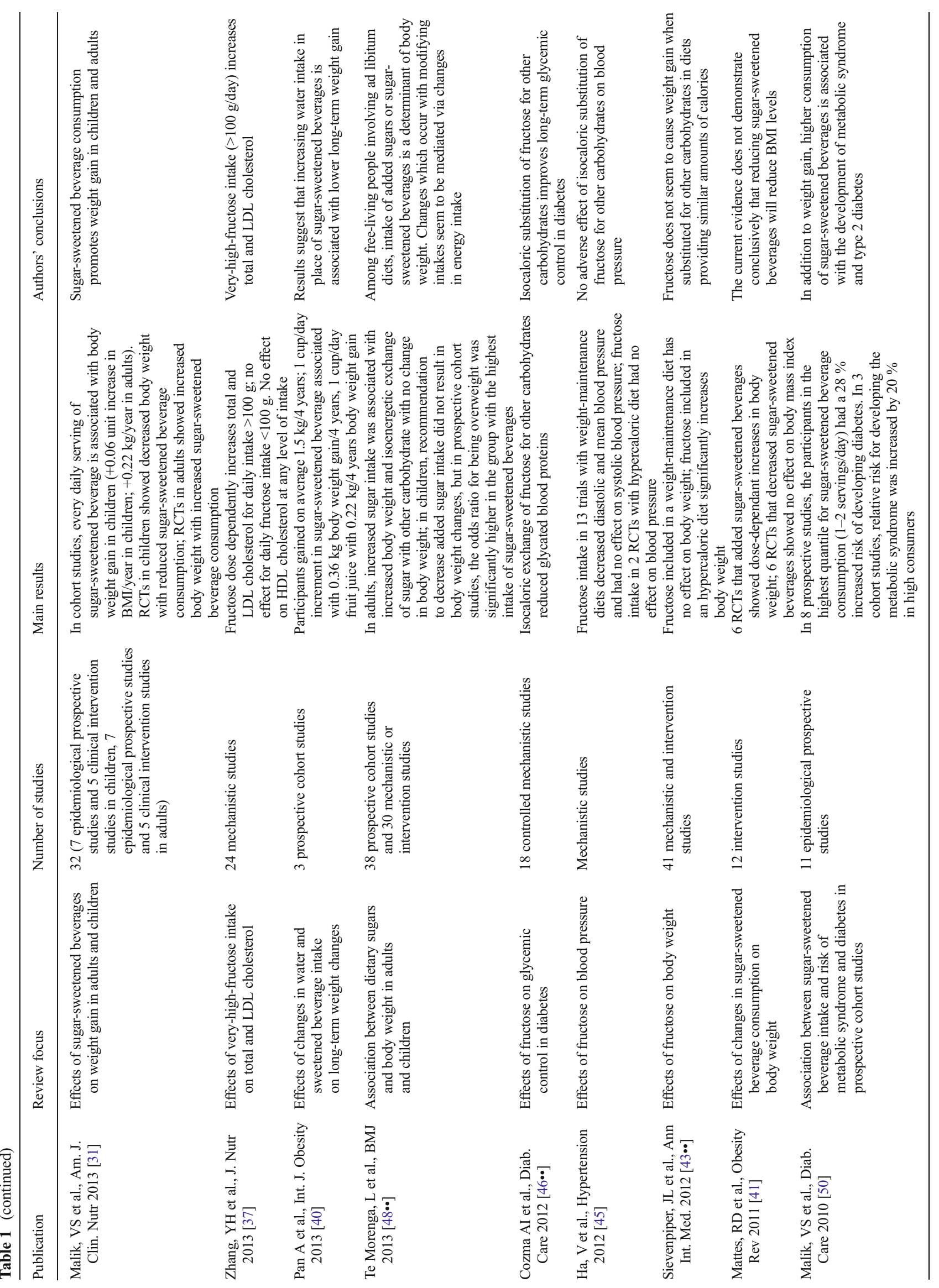


incidence of dyslipidemia, insulin resistance, and type 2 diabetes [58], with incidence or risk factors for cardiovascular diseases [59-62], with cardiovascular mortality [63•], with chronic kidney diseases [39•], and with hyperuricemia and gout [64]. The strength of these associations is generally reduced when data are adjusted for body weight, suggesting that they are, at least in part, secondary to increased body fat mass.

What can be concluded at this stage? The epidemiological data available so far are quite consistent in pointing toward a positive association between FCCS consumption and the development of obesity. The association is particularly robust for SSB. These studies further indicate that the association between SSB consumption and body weight is largely due to SSB being associated with increased total energy intake $[31,48 \bullet \bullet$.

Clinical intervention studies on FCCS regroup various clinical trials aimed at assessing the global effects of changes in FCCS consumption on pre-defined endpoints in specific subsets of the population. The intervention here is focused on FCCS consumption alone (e.g., replacing SSB with water or artificially sweetened beverages, or adding one or several servings of SSB per day), while otherwise leaving spontaneous food and beverage intake and physical activity uncontrolled. Intervention clinical trials answer one specific question, that is: will a specified intervention (e.g., reduction of sugar intake or of SSB intake) be effective in reaching a specified endpoint (e.g., body weight loss or decreased blood triglyceride concentrations)? As such, they are valuable to evaluate whether it may be worth to introduce the intervention into clinical practice or into public health initiatives. Identification of underlying mechanism may however be limited because more than one mechanism may account for variations of the main outcome. For instance, an intervention trial showing a beneficial effect of reducing FCCS intake may indicate that FCCS is specifically obesogenic; the same result may however also be explained to a reduction in total energy intake (which suggests that reduction of energy intake from other nutrients may have had the same effect). Conversely, if the same intervention trial fails to observe beneficial effects of FCCS reduction, this may reflect that FCCS do not exert specific adverse effects; alternatively, this may also be explained by the absence of compliance (i.e., the participants failing to comply with the dietary instructions) or by a compensation of FCCS energy by an increased consumption of other foods.

Many clinical intervention studies have assessed the effects of reducing or increasing SSB intake in adults and children. These studies have been further analyzed in very complete meta-analyses [31, 48••]. Increased consumption of SSB has been shown to result in significant weight gain compared to control in both adults and children, and this effect has been attributed essentially to an increased total energy intake. Changes in body weight observed in some of these studies were however much lower than what would have been 
expected from cumulated total energy from SSB $[65 \bullet \cdot, 66 \bullet$, $67,68]$. Reduction of SSB consumption was generally associated with significant weight loss and reduced total energy intake. Here again, in many trials, weight loss was far less than what would have been expected based on cumulated SSB energy deficit, suggesting either low compliance to SSB restriction or compensatory increase in total energy intake. Reducing SSB intake was however inconsistently efficient in children, most likely due to low compliance in this class of age $[31,48 \cdot \bullet]$.

What have we learned from intervention trials? First, many trials have assessed the effects of adding sugar to the diet. Quite expectedly, increasing sugar consumption was associated with some weight gain. The effects of increasing sugar consumption was not compared to those of increasing starch or fat consumption, and hence, these studies fall short of demonstrating that weight gain is specifically related to sugar. Second, most studies showed a significant reduction of body weight when SSB consumption was reduced, which certainly indicates that the intervention significantly decreased total energy intake. Although the body weights reported in the intervention and control arms were statistically significant, the actual effect on adiposity was often very low: in one study, BMI increased from 30.4 to $30.5 \mathrm{~kg} / \mathrm{m}^{2}$ in obese adolescent who replaced SSBs with water and from 30.1 to $30.6 \mathrm{~kg} / \mathrm{m}^{2}$ in the control group [66・•]; in another study, body weight nonsignificantly increased by $1.3 \%$ in adolescent receiving SSBs for 6 months, compared to 0.2 and $0.6 \%$ in those receiving artificially sweetened sodas or water, respectively [69•]. This casts serious doubt on the clinical efficacy of a reduction of SSB consumption alone.

Controlled mechanistic studies consist of short-term intervention studies in selected groups of individuals, most often healthy subjects, overweight and obese subjects, or subjects with type 2 diabetes. The experimental protocols compare an intervention arm with high FCCS diet to control arms, which can be either a low FCCS weightmaintenance diet or isocaloric high-glucose/high-starch/ high-fat diets. These studies specifically address what might be the consequences of a high FCCS and attempt to identify potential mechanisms underlying the effects of excess FCCS. Given their strictly controlled conditions, each mechanistic study aims at answering a specific question (e.g., what are the effects of isocaloric amounts of sucrose vs. HFCS on blood lipids? Is fructose more lipogenic than isocaloric amount of glucose? Can excess fructose impair insulin sensitivity?). Results from mechanistic studies merely assess whether a specific role of FCCS is plausible as a working hypothesis. They however cannot assess whether such effects are relevant to the general population in free-living conditions.
Total energy intake is an important confounding factor in these studies. Studies having compared excess energy intake from FCCS to weight-maintenance, lowFCCS diets consistently demonstrate that excess FCCS energy consumption can, within a few days to a few weeks, increase body weight and body fat stores [70], enhance hepatic glucose production [71], impair hepatic suppression of glucose production by insulin [71-73], increase fasting and postprandial blood triglyceride concentration $[29,70,74,75]$, increase intrahepatic fat concentration [76 $]$, and cause a rise in blood uric acid concentrations [70, 77]. Two studies suggested that excess fructose may increase visceral fat mass while excess glucose would increase mainly subcutaneous fat [70]. In one of these studies [70], fructose-induced increase in visceral fat was observed only in males, but not in females. Altogether, these mechanistic studies unfortunately cannot sort out the relative roles of FCCS and energy intakes. In addition, many of these studies assessed the effects of pure fructose rather than sucrose or HFCS, and many of them used levels of daily FCCS intake well above consumption observed in the general population.

Hypercaloric FCCS diets consistently caused an increase in blood triglyceride and uric acid concentrations, while hypercaloric high-glucose or high-fat diets did not. One meta-analysis concluded that high-fructose intake was associated with an increased blood triglyceride only when associated with excess energy intake, but had no effects when part of a weight-maintenance diet [34]. In contrast, another study concluded that dietary sugars influence blood lipids independently of body weight [49••]. One meta-analysis specifically addressed the effects of sugar on blood cholesterol and reported that adverse effects of sugars were observed for doses higher than $100 \mathrm{~g} /$ day [37].

Many narrative reviews and position papers propose that insulin resistance is a well-recognized effect of dietary fructose [78-80]. Moderate increases in fasting hepatic glucose production are indeed observed within a few days on a high-fructose diet but are not associated with clinically relevant increases in blood glucose. Surprisingly, all studies having actually assessed muscle insulin sensitivity by hyperinsulinemic-euglycemic clamps failed to report any muscle insulin resistance in healthy individuals after 1-4 weeks on a high-fructose diet [71-73, 81] or in subjects with type 2 diabetes after 3 months [82]. This strongly suggests that fructose per se, independently of long-term weight changes, does not impair insulin's actions in muscle. Interestingly, one study observed a significant muscle insulin resistance in middle-aged, overweight offspring of type 2 diabetes subjects after 6 days on a high-fructose diet [83], while 
another similar study, performed in young, nonoverweight offspring of type 2 diabetes, failed to document any changes [81]. This raises the possibility that fructose's effects may be modulated by both genetic background and additional factors such as age or body fat mass.

Whether FCCS are responsible for an excess food intake through specific effects involving food intake control has been the focus of active research and will not be reviewed comprehensively here. It has been proposed that fructose fails to inhibit the release of the orexigenic gut hormone ghrelin and increases the release of satiating gut hormones such as GLP-1 and PYY to a lesser extent than glucose or starch [29]. This concept has however been challenged by a recent study showing that fructose had substantial effects on these gut hormones in normal-weight adolescent. The same study however reported an impaired suppression of acyl-ghrelin, the active form of ghrelin, in obese, insulin-resistant adolescent [84]. Furthermore, the hypothesis that fructose may exert less suppression of food intake than glucose or complex carbohydrate is based on indirect markers of food intake control, which relates essentially to the so-called homeostatic systems of food intake regulation, located in the brain stem and hypothalamus. Studies with direct measures of food intake and/or satiety feeling failed to document any difference between fructose and other caloric sweeteners in humans $[28,85$, 86]. Food intake regulation results from complex interactions between metabolic, hormonal, and neurologic signals [87]. There is growing evidence that the hedonic system of food intake, located in neocortical structures, and which is involved in food preferences and palatability, plays a prominent role in food intake control [88]. It has further been suggested, based on the fact that oral sugar ingestion stimulates dopaminergic neurons of the reward system of the brain stem, hypothalamus, and cortex, that this may confer to FCCS potentially addictive potential, at least in animals [89-92] and possibly in humans as well [93]. These are early hypotheses, which still need more studies to be fully evaluated. The concept of sugar addiction is highly debated but suffers from lack of clear diagnosis criteria. Finally, there is to date no scientific evidence that in humans, sugars stimulate these neurological pathways to a larger extent than other food substances with similar palatable properties.

The effect of intravenous fructose administration on uric acid production and to cause hyperuricemia has been long known [94]. Interesting novel observations have recently been made to link FCCS-induced uric acid production to metabolic and cardiovascular diseases. According to these novel hypotheses, uric acid may act as a mediator to induce endothelial cell dysfunction, thus preventing insulin-induced muscle vasodilation. This effect of uric acid has been postulated to contribute to fructose-induced insulin resistance and high blood pressure [95]. One isolated clinical study has supported this hypothesis by showing that a shortterm hypercaloric high-fructose diet increased blood pressure and that this effect was prevented by administration of the uric acid synthesis inhibitor allopurinol [77]. This observation must however be tempered by the fact that several other studies failed to observe a significant effect of a high-fructose diet on blood pressure [45]. Besides vascular effects, uric acid has also been proposed to enhance lipogenesis and thus to contribute to dyslipidemia and hepatic steatosis [96, 97, $98 \bullet \bullet$. These novel hypotheses clearly require to be further evaluated, and more human studies are needed to assess their clinical relevance.

What clinically relevant information do these mechanistic studies offer? There is robust evidence that a high-fructose diet can increase blood triglycerides (TG) within a few days, enhance IHCL storage, and increase endogenous glucose production. These changes are highly significant, yet of small magnitudes, and blood triglyceride and glucose concentration, as well as intrahepatic fat content, remain generally within the normal range. They may of course be early markers of insulin resistance and progress with time to the development of metabolic diseases. There is however an alternative explanation which has been widely disregarded until now, i.e., that these changes may reflect mere adaptation to a high-fructose diet.

Unlike fructose, glucose and fatty acids are key energy substrates for animals, and most cells of the human organism synthesize the enzymes required for glycolysis, beta-oxidation, and degradation of glucose- or fatderived acetyl-CoA in the Krebs cycle, coupled to ATP synthesis in the respiratory chain. In contrast, fructose cannot be used as such by most cells and requires to be first pre-processed into glucose, lactate, or fatty acids [99]. Specific fructose-metabolizing enzymes, fructokinase, aldolase B, and triokinase, are present mainly not only in the liver but also in enterocytes and tubular kidney cells where this pre-processing occurs (Fig. 1). In the liver, fructolysis, unlike glycolysis, is neither regulated by insulin nor inhibited by high concentrations of ATP or citrate. Hepatic production of glucose, lactate, and fatty acids is therefore mainly dependant on the amount of fructose ingested with a meal or a drink. The first adaptation that may occur as a result of fructose ingestion is an increase in hepatic glucose production $[71-73,100]$. As fructose is initially converted to lactate and glucose in the liver, the 


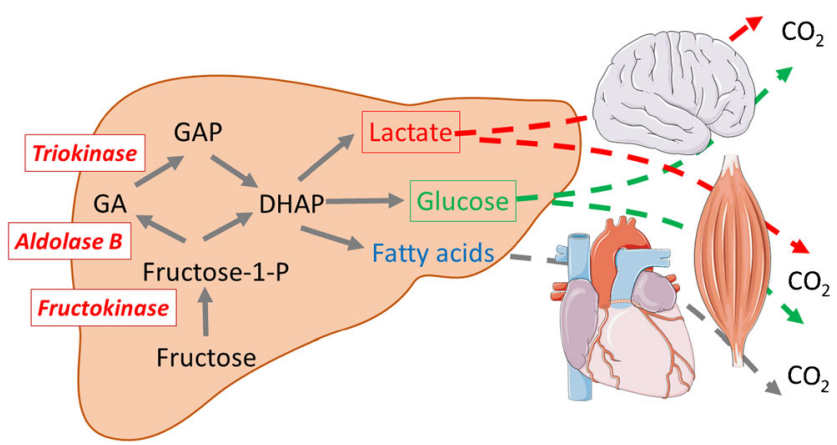

Fig. 1 Unlike glucose, which can be used as an energy substrate by all human cells, fructose cannot be directly metabolized by most cells due to a much lower affinity of hexokinases for fructose than for glucose. Instead, fructose is first metabolized in a limited number of organs (liver, small intestinal mucosa, kidney). In these organs, it is metabolized to trioses-phosphate (di-hydroxyacetone-phosphate and glyceraldehyde-3-phosphate) by a set of specific enzymes: fructokinase (ketohexokinase), aldolase B, and triokinase. Trioses-phosphate can subsequently be further converted into ubiquitous energy substrates: lactate, glucose, and fatty acids (palmitate, oleate, stearate, ...)

resulting increased blood lactate and the modest increase in hepatic glucose production observed in healthy subjects consuming a high-fructose diet do not come as a real surprise. The second adaption consists in the wellcharacterized increase in plasma lipids. However, the metabolic pathways involved markedly differ from those resulting from dietary fat ingestion: fructose conversion into fat occurs essentially in the liver where fructosederived fat is either temporarily stored as intrahepatic

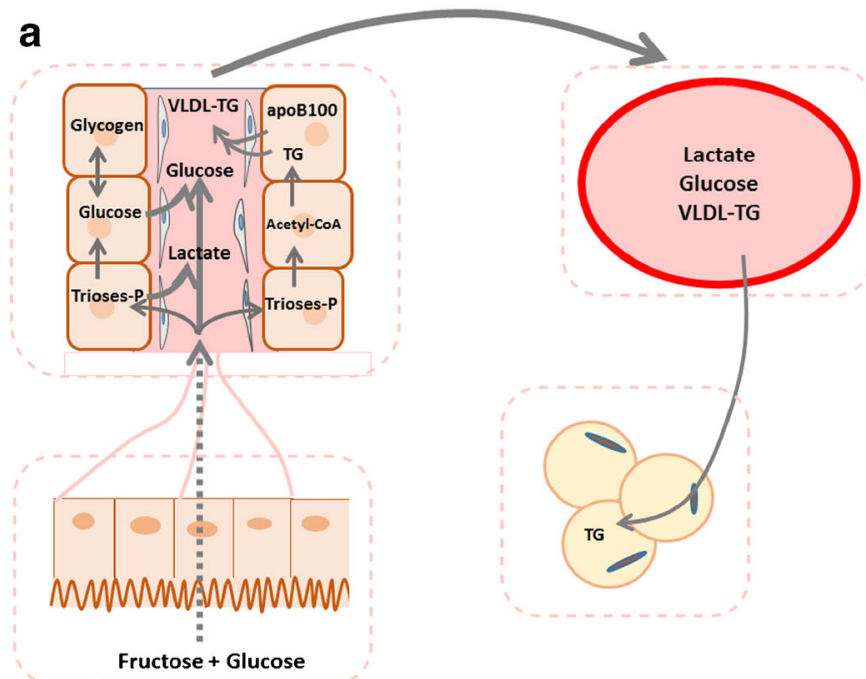

Fig. 2 Pathways used for lipid storage from dietary fructose and dietary fat. Fructose (a) is essentially extracted and metabolized in the liver, where part of it can be converted into lactate, glucose, fatty acids, and triglycerides. Newly synthesized glycogen can be temporarily stored as hepatic glycogen, but its major portion is slowly released into the systemic circulation as glucose. Hepatic fructose handling differs from glucose (whether ingested as free glucose, sucrose, or starch; b), which is only partially extracted by the liver to replenish glycogen stores. Its largest portion however reaches the systemic circulation, elicits an fat and/or secreted into the blood as VLDL triglyceride. In contrast, dietary fats absorbed from the gut are released as chylomicrons in the lymph, thus avoiding first-pass hepatic metabolism to be directly stored in peripheral adipocytes. This difference in the interorgan trafficking involved in the handling and storage of these two lipid sources most likely accounts for increased blood triglyceride concentrations in high-fructose-fed subjects, since chylomicrons-TG have a half-life in circulation considerably faster than VLDL (Fig. 2).

Whether these alterations of glucose and lipid metabolism following fructose ingestion are mere adaptations to a transient change in diet or will in the long term be causally associated with adverse vascular effects remains unknown. If that was the case, it would be important to gather further clinical observation in order to determine whether such deleterious effects of FCCS are restricted to the subgroup of subjects at increased risk due to their genetic background or to specific patterns of FCCS consumption.

\section{Conclusions}

Scientific data regarding the effects of fructose-containing caloric sweeteners presently indicate clearly that

1. Sugar consumption has reached record values in man's history during the second half of the twentieth century

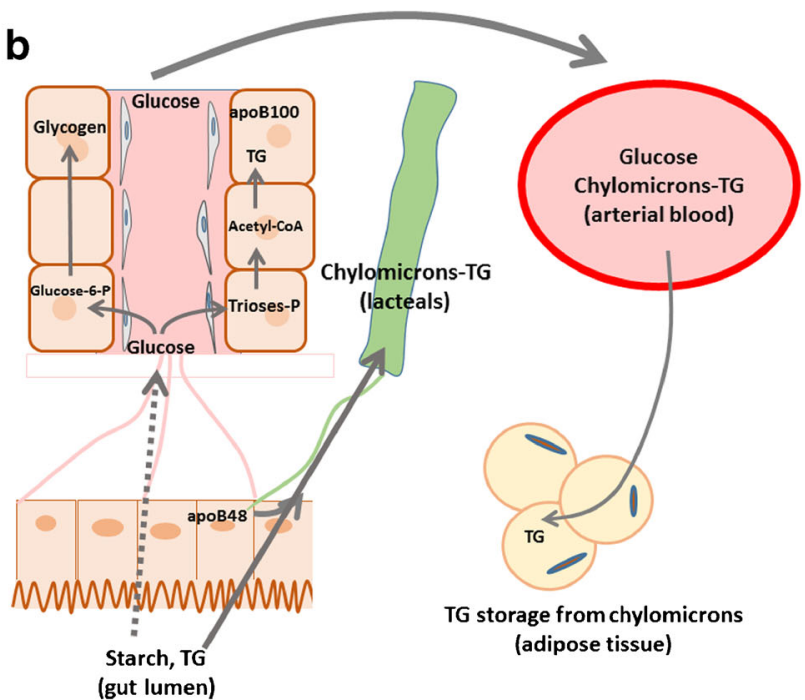

increase in blood glucose and insulin concentration, and is metabolized in insulin-sensitive tissues (muscle, adipose tissue) within a few hours. After fructose ingestion, new fat synthesized de novo in the liver can be temporarily stored within the hepatocytes and/or be secreted with VLDL to be secondarily deposited in adipose tissue (a). In contrast, ingested fat is mainly absorbed as chylomicrons which circulates in the lymph, thus bypassing the liver; chylomicrons-TG will then join the systemic circulation and be deposited in adipose tissue (b) 
and the beginning of the twenty-first century and represents on average close to $20 \%$ total energy intake at the population level in developed countries.

2. Sugar consumption is consistently associated with increased energy intake and with the development of obesity and metabolic diseases in epidemiological studies.

3. Fructose can cause weight gain when present in a highenergy diet providing more calories than required for weight maintenance. There is however no evidence that similar effects would not be observed when replacing sugar with glucose, starch, or lipids.

4. A high-fructose diet can increase blood triglyceride, alter hepatic glucose output, and increase uric acid concentrations. Whether these effects would increase the risk of metabolic or cardiovascular disease independently of an increase in body fat mass remains speculative.

\section{Between Science and Common Sense: Which Practical Steps May Be Considered?}

The scientific data reported in the literature appears somewhat conflicting at first sight. On one hand, there is no strong evidence that, at similar intake levels, sugar exerts worse deleterious effects than other energy substrates. Whether sugar would specifically impair food intake control, or cause tissue lipotoxicity, remains open questions, but levels of evidence are presently too low to lead to specific recommendations. On the other hand, a huge proportion of the population of an ever-increasing number of countries is overweight. As a nutrient accounting to $15-20 \%$ total energy, sugar is certainly contributing to this global excess energy intake [101-103]. Furthermore, many sugary products have a low content of essential nutrients and hence low nutritional quality, which makes them a potential target for energy reduction. This is particularly true of SSBs. There is no strong evidence that energy consumed with beverages is more obesogenic than energy consumed with solid foods and no plausible mechanism to account for such an effect. SSB may nonetheless be easily overconsumed, possibly because beverage intake is stimulated by thirst stimuli, such as blood hyperosmolarity and sodium levels in the distal renal tubules, irrespective of energy balance. As such, SSB reduction is certainly a prime target for the prevention of metabolic disorders, assuming that such decrease will not be compensated by the increase in caloric intake from solid food.

However, if sugars contribute to excess energy intake, there is also compelling evidence that sugar-devoid foods, such as potato chips and meat, are also involved [56••]. Furthermore, interventions focused solely on SSB or sugar intake have failed to achieve clinically relevant weight reduction. The excess body weight of the US population corresponds to a ca.
$350-500 \mathrm{kcal} /$ day excess energy intake on average [104]. In order to revert obesity, energy intake should be reduced by the same amount; in order to reach this target by specifically decreasing sugar intake, added sugar consumption should be reduced to close to zero, which may be unrealistic in the near future. Reduction of SSBs, and reformulation of sugar-rich industrial foods, may certainly contribute to reduced total sugar and energy intake, but it appears obvious that the consumption of other energy-dense foods and/or multifactorial interventions including consumer education, diet, and physical activity will be needed to achieve these goals.

Acknowledgments The work performed on FCCS in LT's laboratory was supported by grants 320030-135782, 320030-138428, 32003B156167, and IZ73Z0-152331 from the Swiss National Science Foundation and 11-06 from the Bundes Amt fur Sport BASPO.

\section{Compliance with Ethics Guidelines}

Conflict of Interest Luc Tappy has received research grants from Nestlé SA, Switzerland, and personal fees from Ferrero, Italy. This work has been written in collaboration with a former colleague presently working with Nestlé SA. This was done as a personal scientific collaboration and was not commissioned nor supported by Nestlé.

Kim-Anne Lê is employed by the Nestlé Research Center, which is a subsidiary of Nestlé Ltd. The submitted work was done independently of Nestlé's interests and represents the author's personal views.

Human and Animal Rights and Informed Consent This article does not contain any studies with human or animal subjects performed by any of the authors

Open Access This article is distributed under the terms of the Creative Commons Attribution 4.0 International License (http:// creativecommons.org/licenses/by/4.0/), which permits unrestricted use, distribution, and reproduction in any medium, provided you give appropriate credit to the original author(s) and the source, provide a link to the Creative Commons license, and indicate if changes were made.

\section{References}

Papers of particular interest, published recently, have been highlighted as:

- Of importance

•. Of major importance

1. Mintz SW. Sweetness and power. The place of sugar in modern history. New York: Penguin; 1985. ISBN 978-0-14-009233-2.

2. Standage T. A history of the world in 6 glasses. New York: Walker \& Company; 2005.

3. Carton P. Les trois aliments meurtriers. Argentière: Imprimerie E Mazel; 1912.

4. Yudkin J. Sugar consumption and myocardial infarction. Lancet. 1971;1:296-7.

5. Yudkin J. Dietary carbohydrate and ischemic heart disease. Am Heart J. 1963;66:835-6.

6. Debry G. Sucres et Santé. Montrouge: J. Libbey; 1997. 
7. Bray GA, Nielsen SJ, Popkin BM. Consumption of high-fructose corn syrup in beverages may play a role in the epidemic of obesity. Am J Clin Nutr. 2004;79:537-43.

8. Yu Z, Lowndes J, Rippe J. High-fructose corn syrup and sucrose have equivalent effects on energy-regulating hormones at normal human consumption levels. Nutr Res. 2013;33:1043-52.

9. Lowndes J, Kawiecki D, Pardo S, Nguyen V, Melanson KJ, Yu Z, et al. The effects of four hypocaloric diets containing different levels of sucrose or high fructose corn syrup on weight loss and related parameters. Nutr J. 2012;11:55.

10. Melanson KJ, Zukley L, Lowndes J, Nguyen V, Angelopoulos TJ, Rippe JM. Effects of high-fructose corn syrup and sucrose consumption on circulating glucose, insulin, leptin, and ghrelin and on appetite in normal-weight women. Nutrition. 2007;23:103-12.

11. Bray GA. Fructose: pure, white, and deadly? Fructose, by any other name, is a health hazard. J Diabetes Sci Technol. 2010;4: $1003-7$

12. Lustig RH. Fat chance: beating the odds against sugar, processed food, obesity, and disease: Fourth Estate. 2013. p. 336.

13. Lustig RH, Schmidt LA, Brindis CD. Public health: the toxic truth about sugar. Nature. 2012;482:27-9.

14. Taubes G. Is sugar toxic. New York Times Magazine. MM47. 2011.

15. EFSA. Scientific opinion on dietary reference values for carbohydrates and dietary fibre ${ }^{1}$. EFSA J. 2010;8:1462. http://www.efsa. europa.eu/fr/search/doc/1462.pdf.

16. Dietary reference intakes for energy, carbohydrates, fiber, fat, fatty acids cholesterol, protein and amino acids (macronutrients). Inst Med. 2005. http://www.nap.edu/catalog/10490/dietary-referenceintakes-for-energy-carbohydrate-fiber-fat-fattyacids-cholesterolprotein-and-amino-acids-macronutrients.

17. Dekker MJ, Su Q, Baker C, Rutledge AC, Adeli K. Fructose: a highly lipogenic nutrient implicated in insulin resistance, hepatic steatosis, and the metabolic syndrome. Am J Physiol Endocrinol Metab. 2010;299:E685-94.

18. Bizeau ME, Pagliassotti MJ. Hepatic adaptations to sucrose and fructose. Metab Clin Exp. 2005;54:1189-201.

19. Tschop M, Heiman ML. Rodent obesity models: an overview. Exp Clin Endocrinol Diabetes. 2001;109:307-19.

20. Woods SC, D'Alessio DA, Tso P, Rushing PA, Clegg DJ, Benoit $\mathrm{SC}$, et al. Consumption of a high-fat diet alters the homeostatic regulation of energy balance. Physiol Behav. 2004;83:573-8.

21. Livesey G, Taylor R. Fructose consumption and consequences for glycation, plasma triacylglycerol, and body weight: meta-analyses and meta-regression models of intervention studies. Am J Clin Nutr. 2008;88:1419-37.

22. Bray GA. Soft drink consumption and obesity: it is all about fructose. Curr Opin Lipidol. 2010;21:51-7.

23. Kaufmann NA, Kapitulnik J. The significance of sucrose in production of hypertriglyceridemia. Acta Med Scand Suppl. 1972;542:229-35.

24. Henry RR, Crapo PA, Thorburn AW. Current issues in fructose metabolism. Annu Rev Nutr. 1991;11:21-39.

25. Uusitupa MI. Fructose in the diabetic diet. Am J Clin Nutr. 1994;59:753S-7.

26. Hellerstein MK. Carbohydrate-induced hypertriglyceridemia: modifying factors and implications for cardiovascular risk. Curr Opin Lipidol. 2002;13:33-40.

27. Fried SK, Rao SP. Sugars, hypertriglyceridemia, and cardiovascular disease. Am J Clin Nutr. 2003;78:873S-80.

28. Lindqvist A, Baelemans A, Erlanson-Albertsson C. Effects of sucrose, glucose and fructose on peripheral and central appetite signals. Regul Pept. 2008;150:26-32.

29. Teff KL, Elliott SS, Tschöp M, Kieffer TJ, Rader D, Heiman M, et al. Dietary fructose reduces circulating insulin and leptin, attenuates postprandial suppression of ghrelin, and increases triglycerides in women. J Clin Endocrinol Metab. 2004;89:2963-72.

30. Xi B, Li S, Liu Z, Tian H, Yin X, Huai P, et al. Intake of fruit juice and incidence of type 2 diabetes: a systematic review and metaanalysis. PLoS One. 2014;9, e93471.

31. Malik VS, Pan A, Willett WC, Hu FB. Sugar-sweetened beverages and weight gain in children and adults: a systematic review and meta-analysis. Am J Clin Nutr. 2013;98:1084-102.

32. Kelishadi R, Mansourian M, Heidari-Beni M. Association of fructose consumption and components of metabolic syndrome in human studies: a systematic review and meta-analysis. Nutrition. 2014;30:503-10.

33. Jayalath VH, Sievenpiper JL, de Souza RJ, Ha V, Mirrahimi A, Santaren ID, et al. Total fructose intake and risk of hypertension: a systematic review and meta-analysis of prospective cohorts. J Am Coll Nutr. 2014;33:328-39.

34. Wang D, Sievenpiper JL, de Souza RJ, Cozma AI, Chiavaroli L, $\mathrm{Ha} \mathrm{V}$, et al. Effect of fructose on postprandial triglycerides: a systematic review and meta-analysis of controlled feeding trials. Atherosclerosis. 2014;232:125-33.

35. Chung M, Ma J, Patel K, Berger S, Lau J, Lichtenstein AH. Fructose, high-fructose corn syrup, sucrose, and nonalcoholic fatty liver disease or indexes of liver health: a systematic review and meta-analysis. Am J Clin Nutr. 2014;100:833-49.

36. Chiu S, Sievenpiper JL, de Souza RJ, Cozma AI, Mirrahimi A, Carleton AJ, et al. Effect of fructose on markers of non-alcoholic fatty liver disease (NAFLD): a systematic review and metaanalysis of controlled feeding trials. Eur J Clin Nutr. 2014;68: 416-23.

37. Zhang YH, An T, Zhang RC, Zhou Q, Huang Y, Zhang J. Very high fructose intake increases serum LDL-cholesterol and total cholesterol: a meta-analysis of controlled feeding trials. J Nutr. 2013;143:1391-8.

38. Wang DD, Sievenpiper JL, de Souza RJ, Chiavaroli L, Ha V, Cozma AI, et al. The effects of fructose intake on serum uric acid vary among controlled dietary trials. J Nutr. 2012;142:916-23.

39. Cheungpasitporn W, Thongprayoon C, O'Corragain OA, Edmonds PJ, Kittanamongkolchai W, Erickson SB. Associations of sugar-sweetened and artificially sweetened soda with chronic kidney disease: a systematic review and meta-analysis. Nephrology (Carlton). 2014;19:791-7. This meta-analysis of prospective studies suggests that consumption of sugarsweetened sodas is associated with the development of chronic kidney disease.

40. Pan A, Malik VS, Hao T, Willett WC, Mozaffarian D, Hu FB. Changes in water and beverage intake and long-term weight changes: results from three prospective cohort studies. Int $\mathrm{J}$ Obes. 2013;37(10):1378-85.

41. Mattes RD, Shikany JM, Kaiser KA, Allison DB. Nutritively sweetened beverage consumption and body weight: a systematic review and meta-analysis of randomized experiments. Obes Rev. 2011;12:346-65.

42. Klein $\mathrm{AV}$, Kiat $\mathrm{H}$. The mechanisms underlying fructose-induced hypertension: a review. J Hypertens. 2015;33(5):912-20.

43.• Sievenpiper JL, de Souza RJ, Mirrahimi A, Yu ME, Carleton AJ, Beyene J, et al. Effect of fructose on body weight in controlled feeding trials: a systematic review and meta-analysis. Ann Intern Med. 2012;156:291-304. This meta-analysis of randomized clinical trials demonstrates that fructose obeys the laws of thermodynamic, and that dietary fructose increases body weight only when excess energy intake is present.

44. Sievenpiper JL, Chiavaroli L, de Souza RJ, Mirrahimi A, Cozma AI, Ha V, et al. 'Catalytic' doses of fructose may benefit glycaemic control without harming cardiometabolic risk factors: a small meta-analysis of randomised controlled feeding trials. Br J Nutr. 2012;108:418-23. 
45. Ha V, Sievenpiper JL, de Souza RJ, Chiavaroli L, Wang DD, Cozma AI, et al. Effect of fructose on blood pressure: a systematic review and meta-analysis of controlled feeding trials. Hypertension. 2012;59:787-95.

46.• Cozma AI, Sievenpiper JL, de Souza RJ, Chiavaroli L, Ha V, Wang DD, et al. Effect of fructose on glycemic control in diabetes: a systematic review and meta-analysis of controlled feeding trials. Diabetes Care. 2012;35:1611-20. This meta-analysis documents that replacing sugar or starch with pure fructose actually improves glycemic control in type 2 diabetes.

47. Sievenpiper JL, Carleton AJ, Chatha S, Jiang HY, de Souza RJ, Beyene J, et al. Heterogeneous effects of fructose on blood lipids in individuals with type 2 diabetes: systematic review and metaanalysis of experimental trials in humans. Diabetes Care. 2009;32: 1930-7.

48.• Te Morenga L, Mallard S, Mann J. Dietary sugars and body weight: systematic review and meta-analyses of randomised controlled trials and cohort studies. Br Med J. 2013;346, e7492. This is a comprehensive meta-analysis of prospective cohort studies and randomized control trials in adults and children. Its main conclusion is that sugar consumption is associated with body weight gain through an increased energy intake.

49.•• Te Morenga LA, Howatson AJ, Jones RM, Mann J. Dietary sugars and cardiometabolic risk: systematic review and meta-analyses of randomized controlled trials of the effects on blood pressure and lipids. Am J Clin Nutr. 2014;100:65-79. This is a comprehensive meta-analysis of prospective cohort studies and randomized control trials in adults and children. It concludes that dietary sugars influence blood pressure and serum lipids independently of body weight.

50. Malik VS, Popkin BM, Bray GA, Despres JP, Willett WC, Hu FB. Sugar-sweetened beverages and risk of metabolic syndrome and type 2 diabetes: a meta-analysis. Diabetes Care. 2010;33:247783.

51. Greenwood DC, Threapleton DE, Evans CEL, Cleghorn CL, Nykjaer C, Woodhead C, Burley VJ. Association between sugar-sweetened and artificially sweetened soft drinks and type 2 diabetes: systematic review and dose-response meta-analysis of prospective studies. Br J Nutr. 2014;112:725-734.

52. Forshee RA, Anderson PA, Storey ML. Sugar-sweetened beverages and body mass index in children and adolescents: a metaanalysis. Am J Clin Nutr. 2008;87:1662-1671.

53. Mann CJ. Observational research methods. Research design II: cohort, cross sectional, and case-control studies. Emerg Med J. 2003;20:54-60

54. Ho PM, Peterson PN, Masoudi FA. Evaluating the evidence: is there a rigid hierarchy? Circulation. 2008;118:1675-84.

55. Palmer JR, Boggs DA, Krishnan S, Hu FB, Singer M, Rosenberg L. Sugar-sweetened beverages and incidence of type 2 diabetes mellitus in African American women. Arch Intern Med. 2008;168:1487-92.

56.• Mozaffarian D, Hao T, Rimm EB, Willett WC, Hu FB. Changes in diet and lifestyle and long-term weight gain in women and men. $\mathrm{N}$ Engl J Med. 2011;364:2392-404. Prospective cohort studies identifying foods which are associated with body weight gain. It documents that SSB, potatoes (chips and french fries), and meat are all associated with weight gain.

57. Libuda L, Alexy U, Buyken AE, Sichert-Hellert W, Stehle P, Kersting M. Consumption of sugar-sweetened beverages and its association with nutrient intakes and diet quality in German children and adolescents. Br J Nutr. 2009;101:1549-57.

58. Schulze MB, Manson JE, Ludwig DS, Colditz GA, Stampfer MJ, Willett WC, et al. Sugar-sweetened beverages, weight gain, and incidence of type 2 diabetes in young and middle-aged women. JAMA. 2004;292:927-34.
59. Fung TT, Malik V, Rexrode KM, Manson JE, Willett WC, Hu FB. Sweetened beverage consumption and risk of coronary heart disease in women. Am J Clin Nutr. 2009;89:1037-42.

60. de Koning L, Malik VS, Kellogg MD, Rimm EB, Willett WC, Hu FB. Sweetened beverage consumption, incident coronary heart disease, and biomarkers of risk in men. Circulation. 2012;125(1735-1741):S1731.

61. Ambrosini GL, Oddy WH, Huang RC, Mori TA, Beilin LJ, Jebb SA. Prospective associations between sugar-sweetened beverage intakes and cardiometabolic risk factors in adolescents. Am J Clin Nutr. 2013;98:327-34.

62. de Koning L, Malik VS, Rimm EB, Willett WC, Hu FB. Sugarsweetened and artificially sweetened beverage consumption and risk of type 2 diabetes in men. Am J Clin Nutr. 2011;93:1321-7.

63. Yang Q, Zhang Z, Gregg EW, Flanders WD, Merritt R, Hu FB. Added sugar intake and cardiovascular diseases mortality among US adults. JAMA Intern Med. 2014;174:516-24. This prospective study on a large cohort of participants documents a significant relationship between added sugar consumption and increased risk for CVD mortality.

64. Lin WT, Huang HL, Huang MC, Chan TF, Ciou SY, Lee CY, et al. Effects on uric acid, body mass index and blood pressure in adolescents of consuming beverages sweetened with high-fructose corn syrup. Int J Obes. 2013;37:532-39.

$65 . \bullet$ de Ruyter JC, Olthof MR, Seidell JC, Katan MB. A trial of sugarfree or sugar-sweetened beverages and body weight in children. $\mathrm{N}$ Engl J Med. 2012. This randomized clinical trial documents a significant increase of body weight in children consuming SSB compared to artificially sweetened beverages. The absolute effects on body weight is however small.

66.• Ebbeling CB, Feldman HA, Chomitz VR, Antonelli TA, Gortmaker SL, Osganian SK, et al. A randomized trial of sugarsweetened beverages and adolescent body weight. N Engl J Med. 2012. This randomized clinical trial documents a lesser increase in BMI over 1 year in adolescents replacing SSB with water. The absolute effect on BMI is very small, and results after 2 years are non-significant.

67. Paineau DL, Beaufils F, Boulier A, Cassuto DA, Chwalow J, Combris $\mathrm{P}$, et al. Family dietary coaching to improve nutritional intakes and body weight control: a randomized controlled trial. Arch Pediatr Adolesc Med. 2008;162:34 43.

68. Sichieri R, Paula Trotte A, de Souza RA, Veiga GV. School randomised trial on prevention of excessive weight gain by discouraging students from drinking sodas. Public Health Nutr. 2009;12:197-202.

69. Maersk M, Belza A, Stodkilde-Jorgensen H, Ringgaard S, Chabanova E, Thomsen H, et al. Sucrose-sweetened beverages increase fat storage in the liver, muscle, and visceral fat depot: a 6-mo randomized intervention study. Am J Clin Nutr. 2012;95: 283-9. This is a clinical trial study suggesting that fructose may specifically cause visceral fat accumulation.

70. Stanhope KL, Schwarz JM, Keim NL, Griffen SC, Bremer AA, Graham JL, et al. Consuming fructose-sweetened, not glucosesweetened, beverages increases visceral adiposity and lipids and decreases insulin sensitivity in overweight/obese humans. J Clin Invest. 2009;119:1322-34.

71. Faeh D, Minehira K, Schwarz JM, Periasamy R, Park S, Tappy L. Effect of fructose overfeeding and fish oil administration on hepatic de novo lipogenesis and insulin sensitivity in healthy men. Diabetes. 2005;54:1907-13.

72. Aeberli I, Hochuli M, Gerber PA, Sze L, Murer SB, Tappy L, et al. Moderate amounts of fructose consumption impair insulin sensitivity in healthy young men: a randomized controlled trial. Diabetes Care. 2013;36:150-56.

73. Le KA, Faeh D, Stettler R, Ith M, Kreis R, Vermathen P, et al. A 4wk high-fructose diet alters lipid metabolism without affecting 
insulin sensitivity or ectopic lipids in healthy humans. Am J Clin Nutr. 2006;84:1374-9.

74. Teff KL, Grudziak J, Townsend RR, Dunn TN, Grant RW, Adams $\mathrm{SH}$, et al. Endocrine and metabolic effects of consuming fructoseand glucose-sweetened beverages with meals in obese men and women: influence of insulin resistance on plasma triglyceride responses. J Clin Endocrinol Metab. 2009;94:1562-9.

75. Lecoultre V, Carrel G, Egli L, Binnert C, Boss A, Macmillan EL, et al. Coffee consumption attenuates short-term fructose-induced liver insulin resistance in healthy men. Am J Clin Nutr. 2014;99: $268-75$

76. Lecoultre V, Egli L, Carrel G, Theytaz F, Kreis R, Schneiter P, et al. Effects of fructose and glucose overfeeding on hepatic insulin sensitivity and intrahepatic lipids in healthy humans. Obesity. 2013;21:782-5. This study documents that short-term overfeeding with fructose, glucose, or fat increases intrahepatic fat content in healthy subjects.

77. Perez-Pozo SE, Schold J, Nakagawa T, Sanchez-Lozada LG, Johnson RJ, Lillo JL. Excessive fructose intake induces the features of metabolic syndrome in healthy adult men: role of uric acid in the hypertensive response. Int J Obes. 2010;34:454-61.

78. Lustig RH. Fructose: metabolic, hedonic, and societal parallels with ethanol. J Am Diet Assoc. 2010;110:1307-21.

79. Stanhope KL. Role of fructose-containing sugars in the epidemics of obesity and metabolic syndrome. Ann Rev Nutr. 2012;63:329 43.

80. Rebollo A, Roglans N, Alegret M, Laguna JC. Way back for fructose and liver metabolism: bench side to molecular insights. World J Gastroenterol : WJG. 2012;18:6552-9.

81. Le KA, Ith M, Kreis R, Faeh D, Bortolotti M, Tran C, et al. Fructose overconsumption causes dyslipidemia and ectopic lipid deposition in healthy subjects with and without a family history of type 2 diabetes. Am J Clin Nutr. 2009;89:1760-5.

82. Thorburn AW, Crapo PA, Griver K, Wallace P, Henry RR. Longterm effects of dietary fructose on carbohydrate metabolism in non-insulin-dependent diabetes mellitus. Metabolism. 1990;39: $58-63$.

83. Hokayem M, Blond E, Vidal H, Lambert K, Meugnier E, FeilletCoudray $\mathrm{C}$, et al. Grape polyphenols prevent fructose-induced oxidative stress and insulin resistance in first-degree relatives of type 2 diabetic patients. Diabetes Care. 2013;36:1454-61.

84. Van Name M, Giannini C, Santoro N, Jastreboff AM, Kubat J, Li $\mathrm{F}$, et al. Blunted suppression of acyl-ghrelin in response to fructose ingestion in obese adolescents: the role of insulin resistance. Obesity (Silver Spring). 2015;23:653-61.

85. Akhavan T, Anderson GH. Effects of glucose-to-fructose ratios in solutions on subjective satiety, food intake, and satiety hormones in young men. Am J Clin Nutr. 2007;86:1354-63.

86. Bowen J, Noakes M, Clifton PM. Appetite hormones and energy intake in obese men after consumption of fructose, glucose and whey protein beverages. Int J Obes (Lond). 2007;31:1696-703.

87. French SA, Epstein LH, Jeffery RW, Blundell JE, Wardle J. Eating behavior dimensions. Associations with energy intake and body weight. A review. Appetite. 2012;59:541-9.

88. Kenny PJ. Reward mechanisms in obesity: new insights and future directions. Neuron. 2011;69:664-79.
89. Lenoir M, Serre F, Cantin L, Ahmed SH. Intense sweetness surpasses cocaine reward. PLoS One. 2007;2, e698.

90. Cantin L, Lenoir M, Augier E, Vanhille N, Dubreucq S, Serre F, et al. Cocaine is low on the value ladder of rats: possible evidence for resilience to addiction. PLoS One. 2010;5, e11592.

91. Ahmed SH, Guillem K, Vandaele Y. Sugar addiction: pushing the drug-sugar analogy to the limit. Curr Opin Clin Nutr Metab Care. 2013;16:434-9.

92. Ahmed S, Kashem MA, Sarker R, Ahmed EU, Hargreaves GA, McGregor IS. Neuroadaptations in the striatal proteome of the rat following prolonged excessive sucrose intake. Neurochem Res. 2014;39:815-24.

93. Fortuna JL. Sweet preference, sugar addiction and the familial history of alcohol dependence: shared neural pathways and genes. J Psychoactive Drugs. 2010;42:147-51.

94. Van den Berghe G. Metabolic effects of fructose in the liver. Curr Top Cell Regul. 1978;13:97-135.

95. Nakagawa $\mathrm{T}, \mathrm{Hu} \mathrm{H}$, Zharikov S, Tuttle KR, Short RA, Glushakova $\mathrm{O}$, et al. A causal role for uric acid in fructoseinduced metabolic syndrome. Am J Physiol Renal Physiol. 2006;290:F625-31.

96. Lanaspa MA, Sanchez-Lozada LG, Cicerchi C, Li N, RoncalJimenez CA, Ishimoto $\mathrm{T}$, et al. Uric acid stimulates fructokinase and accelerates fructose metabolism in the development of fatty liver. PLoS ONE. 2012;7, e47948.

97. Lanaspa MA, Sanchez-Lozada LG, Choi YJ, Cicerchi C, Kanbay $\mathrm{M}$, Roncal-Jimenez CA, et al. Uric acid induces hepatic steatosis by generation of mitochondrial oxidative stress: potential role in fructose-dependent and -independent fatty liver. J Biol Chem. 2012;287:40732-44.

98.• Lanaspa MA, Cicerchi C, Garcia G, Li N, Roncal-Jimenez CA, Rivard CJ, et al. Counteracting roles of AMP deaminase and AMP kinase in the development of fatty liver. PLoS ONE. 2012;7, e48801. These three studies provide evidence that uric acid may act as a metabolic regulator in the liver. The role of uric acid in fructose-induced metabolic changes remains to be further evaluated.

99. Mayes PA. Intermediary metabolism of fructose. Am J Clin Nutr. 1993;58:754S-65.

100. Dirlewanger M, Schneiter P, Jequier E, Tappy L. Effects of fructose on hepatic glucose metabolism in humans. Am J Physiol Endocrinol Metab. 2000;279:E907-11.

101. Welsh JA, Sharma AJ, Grellinger L, Vos MB. Consumption of added sugars is decreasing in the United States. Am J Clin Nutr. 2011;94:726-34.

102. Welsh JA, Sharma A, Cunningham SA, Vos MB. Consumption of added sugars and indicators of cardiovascular disease risk among US adolescents. Circulation. 2011;123:249-57.

103. Vos MB, Kimmons JE, Gillespie C, Welsh J, Blanck HM. Dietary fructose consumption among US children and adults: the Third National Health and Nutrition Examination Survey. Medscape J Med. 2008;10:160.

104. Swinburn B, Sacks G, Ravussin E. Increased food energy supply is more than sufficient to explain the US epidemic of obesity. Am J Clin Nutr. 2009;90:1453-6. 